\title{
Social Relation Cognitive Model on Virtual Prototyping Technology in Construction Project
}

\author{
http://dx.doi.org/10.3991/ijoe.v9i3.2883 \\ Lei Zhang ${ }^{1,2}$, Honglei Liu ${ }^{1, *}$, Guangbin Wang ${ }^{1}$ \\ ${ }^{1}$ Tongji University, Shanghai, China \\ ${ }^{2}$ Shandong Jianzhu University, Jinan, China
}

\begin{abstract}
It is valuable to study social relation cognition of participants about virtual prototyping technology in construction projects to promote its acceptance and application. Building information modeling (BIM) is a transformative virtual prototyping technology for construction industry. The analysis of social relation is closely related to BIM application to stakeholders, which involves many cognitive indicators, i.e. organizations, spaces and behaviors. Based on social network analysis, a cognitive model for actors' social relation to BIM knowledge is proposed $\square$ Using survey data, this paper explores the cognitive ability between participants. Through statistical analysis of indictors in the model, it is found that significant difference of virtual prototyping technology in social relation cognition exists.
\end{abstract}

Index Terms-Cognitive Model, Social Relation, Building Information Modeling, Construction Project, Social Network.

\section{INTRODUCTION}

Virtual prototyping (VP) is a computer-aided design process concerned with the construction of digital models and realistic graphical simulation [1]. VP technology has been extensively applied to the automobile and aerospace industries. Several studies have used VP technology to develop effective dynamic project design and construction, such as the Virtual Design and Construction (VDC) [2], Virtual Construction Environment (VCE) [3], Virtual Facility Prototyping (VFP) [4], and DIVERCITY [5]. However, VP technology in construction industry only played a limited role until the application of building information modeling (BIM) was widely accepted by stakeholders.

BIM is regarded as an important technology of the last decade in the construction industry (Eastman et al., 2008; Jernigan, 2007; Guo et al., 2010). BIM is one of the important areas in currently Virtual Reality (VR) research and is expected to envision efficient collaboration, improved data integrity, distributed access and retrieval of building data and high quality project outcome through enhanced performance analysis, as well as multidisciplinary planning and coordination [5][6]. It is necessary to explore the cognitive model on BIM to understand the different cognitive abilities among actors in construction projects.

Recently, the network analysis approach has been receiving attention within the construction industry, where concepts such as communication between project participants are receiving significant attention (Morton et al. 2006; Katsanis 2006). Social cognitive theory provides a conceptual framework in which the determinants and mechanism of such effect can be examined. People's behavior is shaped and controlled by either environmental influence or internal dispositions. Social relation cognitive modeling belongs to social computing domain and it studies the regular pattern of agents' social behavior via computer technology and solve various problems with inter-group communication and collaboration.

The motivation for this research centers on the social relation and indicators in cognitive model on virtual prototyping technology (especially BIM) beyond the traditional construction perspective on project management.

\section{LITERATURE REVIEW OF SOCIAL RELATION COGNITIVE}

Following the successful implementation of virtual prototyping in the manufacturing industry, many studies in the construction industry put their efforts on using VP to produce an effective dynamic construction project. BIM has been the direction of the future development in construction industry, but many factors affect the BIM cognition model, especially in aspects of the interoperability between software, BIM value and interorganizational collaboration $\square$ Gilligan et al., 2007; Han, Y.et al., 2008; McGraw-Hill, 2011; Guanpei He, 2012; Jiayi Pan, 2012; Qinghua He, 2012; Zhiliang Ma, 2010

In recent years, some organizations and academics developed the related research on social cognitive model of VP technology. In the surveys to North America, Middle East and Europe, McGraw-Hill $(2009,2010)$ reported that users' cognitive differences were existed in Return on Investment (ROI), potential value, internal revenue, expected value and other cognitive aspects. Social relation cognitive model also depends on the environment factors [7][8]. AWCI (2009) analyzed BIM application in curtain wall industry and found that the agents have disagreement with BIM social relation and cognition [9]. Ning GU \& Kerry London (2010) focused on the VP technology perception, cognition and interest between stakeholders and found that the architects and vendors are the most active organizations [10]. Shady Attia (2010) made two questionnaires and analyzed the cognitive experiences and behaviors of architects and engineers. There are significant differences in the aspects of simulation tools, information management, knowledge integration and models sharing [11]. J Won, G Lee (2010) studied the success factors of BIM application provided by 61 international experts [12]. Gilligan and Kunz (2007) and Damian (2008) explored the values and barriers of BIM in order to examine the understanding of social relations [13][14].

In an inter-organization network, cognition of VP technology is exchanged and therefore organizations in the 
network can learn from each other (Appleyard 1996; Mowery et al. 1996; Taylor et al. 2009; Uzzi and Gillespie 2002; Zucker et al. 1996). Social Network Analysis (SNA) has been an instrumental tool for researchers focusing on the interactions of a set of actors (Moreno 1960; Hu and Rachera 2008; Nooy et al. 2005). Meanwhile, hybrid approaches were also suggested to connect social network theory with learning dynamics and BIM in projects (Taylor et al. 2009; Taylor and Bernstein 2009).

\section{Social Relation Cognitive Model}

The studies above about cognitive model on VP technology use questionnaires and more qualitative analysis, mainly focused on the level of understanding of VP technology, value perception and judgment, barriers, influencing factors, etc. Studies generally agree that the stakeholders of government, owner, contractor, architect, investigator and vendors participating subjects on VP technology were in different positions, and less quantitative analysis methods were used.

\section{A. Social relation}

According to Wasserman and Faust (1997), a social network is a social structure made of actors (nodes) that are connected by one or more specific type of relations (ties), such as friendship, firm alliance, or international trade. The study utilizes UCINET software to explore the network diagrams, the individual networks and cohesion subgroups.

Density and centrality are the most common indicators of a network's connectivity. They represent the extent of how densely and cohesively nodes in a network are interconnected (Pryke 2004), as shown in the following equation:

$$
\text { a. } \quad \text { Density }=l /(n(n-1) / 2)
$$

where $l=$ number of existent lines and $\mathrm{n}=$ number of existent nodes.

$$
\text { b. Degree Centrality }=\sum_{j=1}^{n}\left(T_{i j}+T_{j i}\right) / \sum_{i=1}^{n} \sum_{j=1}^{n}
$$

where $\mathrm{T}_{i j}=$ number of degree that a node $i$ receives from a node $j$ and $n=$ number of existent nodes.

$$
\text { c. Betweenness Centrality }=\sum_{s, t, s \neq t \neq i} \frac{\sigma_{i}(s, t)}{\sigma(s, t)}
$$

where $\sigma_{i}(s, t)=$ number of shortest paths from node $s$ to node that pass through node $i$.

$$
\text { d. Closeness centrality }=\frac{n-1}{\sum_{k \in N} d(i, k)}
$$

where $n=$ number of nodes; $N=$ total nodes; $k=k$ th node in the network; and $d(i, k)=$ the length of the shortest path between node $i$ and $k$.

\section{B. Identify indicators}

Kerzner (1998) selected indicators for a project organizational structure; Won et al. (2009) summarized the 19 critical success factors for cognitive analysis comparing the data of South Korea and other countries; Ahadzie et al. (2007) and E. Adinyira et al. (2010) provided 13 critical success criteria to VP in public housing building projects; Helen \&Thomas (2010) identified factors of SIOM, Pollaphat Nitithamyong (2006) confirmed 42 indicators that can potentially affect performance of WPMSs basedon VP and IT.

\section{Evaluation method and mathematical model}

Principal Component Analysis (PCA) is a mathematical procedure that uses an orthogonal transformation to convert a set of observations of possibly correlated variables into a set of values of linearly uncorrelated variables called principal components.PCA may get the largest contribution of variance to datasets by keeping low level principal components and ignoring high level ones.

a. Data collection and standardization of original indicators: According to the data demand, the paper establishes the sample matrix and standardizes transformation as following.

$$
\begin{gathered}
\mathrm{Z}_{i j}=\frac{x_{i j}-\overline{x_{j}}}{s_{j}}, i=1,2,3 \ldots, n, j=1,2,3 \ldots, p \\
\overline{x_{J}}=\frac{\sum_{i=1}^{n} x_{i j}}{n}, s_{j}^{2}=\frac{\sum_{i=1}^{n}\left(x_{i j}-\overline{x_{j}}\right)^{2}}{b-1}
\end{gathered}
$$

where Random vector $x=\left(x_{1}, x_{2}, \ldots, x_{m}\right)^{T}, \mathrm{n}$ samples $x_{i}=\left(x_{i 1}, x_{i 2}, \ldots, x_{i p}\right)^{T}$.

b. Correlation matrix:

$$
\mathrm{R}=\left[r_{i j}\right]_{p} x_{p}=\frac{Z^{T} Z}{n-1}
$$

Where $\boldsymbol{r}_{\boldsymbol{i} j}=\frac{\sum z_{\boldsymbol{k} j} \cdot \boldsymbol{z}_{\boldsymbol{k}}}{\boldsymbol{n - 1}}$.

c. Solution of eigenvector equation:

$$
\left|\boldsymbol{R}-\lambda \boldsymbol{I}_{\boldsymbol{p}}\right|=\mathbf{0} ; \boldsymbol{R} \boldsymbol{b}=\lambda_{j} \boldsymbol{b}
$$

0.85.

where cumulative contribution rate $\rho=\frac{\sum_{j=1}^{m} \lambda_{j}}{\sum_{j=1}^{p} \lambda_{j}} \geq$

d. Transform indicator variables into principal components:

$$
\boldsymbol{U}_{\boldsymbol{i} j}=\boldsymbol{z}_{\boldsymbol{i}}^{\boldsymbol{T}} \boldsymbol{b}_{\boldsymbol{j}}^{\mathbf{0}}
$$

where $\boldsymbol{U}_{\boldsymbol{m}}$ named $m$ th principal component, and $\boldsymbol{b}_{\boldsymbol{j}}^{\mathbf{0}}$ is the unit eigenvectors for each $\boldsymbol{\lambda}_{\boldsymbol{j}}(\boldsymbol{j}=\mathbf{1}, \mathbf{2}, \mathbf{3} \cdots \boldsymbol{m})$.

e. Comprehensive evaluation to $m$ principal components: We can get the overall score to each principal component weighted.

$$
\begin{aligned}
& \mathrm{U}=\sum_{j=1}^{n} \boldsymbol{U}_{\boldsymbol{i}} \\
& \boldsymbol{U}_{\boldsymbol{i}}=\sum_{j=1}^{n} \boldsymbol{V}_{\boldsymbol{i}} \boldsymbol{W}_{\boldsymbol{i} j}
\end{aligned}
$$

where $\boldsymbol{U}_{\boldsymbol{i}}=$ value of the system; $\boldsymbol{V}_{\boldsymbol{i} \boldsymbol{j}}=$ correlation coefficient of $j$ th factor to indicator; $\boldsymbol{W}_{\boldsymbol{i} j}=$ contribution rate of $j$ th factor; $\mathbf{n}=$ sum of factors.

\section{CASE AnAlysis on Social RELATION Cognitive MODEL}

\section{A. Background of the project}

The Shanghai Center is the tallest building under construction in Shanghai, China, which was started in Nov 2008. It will be 632 meters in height and have a total of 121 stories. The investment will reach 14.8 billion Yuan. The project tries to follow sustainable development concepts in its full life cycle of construction and achieve high efficiency of material consumption. As a result, many VP technologies, especial BIM, are widely used in order to ensure the targets of the project are successfully achieved.

\section{B. Outline of the Survey}

By interview with certain VP experts, we determine the survey to explore the social relations of VP technology (this paper taking BIM as an example) based on the above researches. The questionnaire consists of three parts, as 
follows: firstly, with whom you interact the BIM cognition in your position; secondly, the richness of the amount of knowledge you offered (divided into the level of low, medium and high); thirdly, your opinion of the indicators in BIM communication (Table I), using mensuration of Liker scale 5 levels to indicate the degree of satisfaction to interactive knowledge of VP technology.

In this project, 42 people were involved in VP technology including the owner, contractors, designers, operators and some others (Table II). All actors responded and $100 \%$ of the questionnaires were valid.

\section{Social relation network}

For this study, UCINET 6 is provided for mathematical measurements. As illustrated in Fig.1, structural concerns within the project network are identified. Except the two isolated nodes of S5 and S6, most nodes have significant relations in VP technology communication with others. The node O6 (BIM manager) is in the core of the network, which exchanges VP technology cognition with many nodes in the network and promotes the two-way flow of knowledge. The nodes of D1 and C5 also occupy important positions.

Using degree centrality of SNA, we can make quantitative analysis of the inputs or outputs of each agent's cognition and find out the key network members in organizational cognition. The density of the network is $0.387(\mathrm{~N}$ of Ties is 144 and Avg Degree is 3.93), and network Centralization is $25.85 \%$. This shows that the link between agents of the network is not very close. Some nodes rely on only a few ones (C5, O6, D1), which means cognitive transformation and exchange are less frequent.

As shown in Fig 2, Betweenness Centrality represents the control degree to knowledge transfer channels of a node. The actor of BIM manager (O6) has the highest Betweenness, about $46.377 \%$, and the nodes of D1, C5, $\mathrm{D} 8, \mathrm{O} 1$ and $\mathrm{C} 1$ also reach more than $10 \%$. It indicates that these members in the network occupy the positions of structural holes in the exchange of knowledge within the organization and play important roles as bridges in delivery processes. They control the flow of knowledge effectively to others.
TABLE I.

INDICATORS TO VP TECHNOLOGY SOCIAL RELATIONS

\begin{tabular}{|l|l|l|l|}
\hline Code & Indicators & Code & Indicators \\
\hline $\mathrm{X}_{1}$ & $\begin{array}{l}\text { Interoperability of vari- } \\
\text { ous software }\end{array}$ & $\mathrm{X}_{15}$ & Industry promotion \\
\hline $\mathrm{X}_{2}$ & Software defects & $\mathrm{X}_{16}$ & $\begin{array}{l}\text { Construction industry pro- } \\
\text { duced extensive }\end{array}$ \\
\hline $\mathrm{X}_{3}$ & $\begin{array}{l}\text { Domestic software sup- } \\
\text { porting }\end{array}$ & $\mathrm{X}_{17}$ & $\begin{array}{l}\text { The complexity of construction } \\
\text { industry management mode }\end{array}$ \\
\hline $\mathrm{X}_{4}$ & Software costs & $\mathrm{X}_{18}$ & $\begin{array}{l}\text { National planning and strategic } \\
\text { guidance }\end{array}$ \\
\hline $\mathrm{X}_{5}$ & Hardware costs & $\mathrm{X}_{19}$ & Education and promotion \\
\hline $\mathrm{X}_{6}$ & $\begin{array}{l}\text { Standards and specifica- } \\
\text { tions }\end{array}$ & $\mathrm{X}_{20}$ & International exchange \\
\hline $\mathrm{X}_{7}$ & $\begin{array}{l}\text { Information security and } \\
\text { intellectual property } \\
\text { rights }\end{array}$ & $\mathrm{X}_{21}$ & $\begin{array}{l}\text { Incentive mechanism within } \\
\text { the enterprise }\end{array}$ \\
\hline $\mathrm{X}_{8}$ & Value measurability & $\mathrm{X}_{22}$ & Firm support \\
\hline $\mathrm{X}_{9}$ & $\begin{array}{l}\text { Necessary guidance } \\
\text { convenience }\end{array}$ & $\mathrm{X}_{23}$ & Owners dominant \\
\hline $\mathrm{X}_{10}$ & $\begin{array}{l}\text { Ability of staff to adapt } \\
\text { knowledge }\end{array}$ & $\mathrm{X}_{24}$ & $\begin{array}{l}\text { Difficulties in Organizational } \\
\text { communication and coordina- } \\
\text { tion }\end{array}$ \\
\hline $\mathrm{X}_{11}$ & $\begin{array}{l}\text { Engineer talent shortage } \\
\mathrm{X}_{12}\end{array}$ & $\begin{array}{l}\text { Standard of contract } \\
\text { language }\end{array}$ & $\begin{array}{l}\text { Responsibilities of participants } \\
\text { are clear }\end{array}$ \\
\hline $\mathrm{X}_{13}$ & $\begin{array}{l}\text { Contract for the respon- } \\
\text { sibilities and privileges }\end{array}$ & $\mathrm{X}_{27}$ & $\begin{array}{l}\text { Model of design and construc- } \\
\text { tion disjointed }\end{array}$ \\
\hline $\mathrm{X}_{14}$ & $\begin{array}{l}\text { Distribution of risks and } \\
\text { benefits }\end{array}$ & Tradional business process \\
\hline
\end{tabular}

TABLE II.

ACTORS TO VP TECHNOLOGY COMMUNICATION

\begin{tabular}{|c|l|}
\hline Organization & \multicolumn{1}{|c|}{ Actors VP technology } \\
\hline Owner $\left(\mathrm{O}_{1} \square \mathrm{O}_{9}\right)$ & $\begin{array}{l}\text { Project manager, Design manager, Site management } \\
\text { manager, Commerce manager, BIM manager, BIM } \\
\text { structural engineer, MEP Engineer, Architectural engi- } \\
\text { neer. }\end{array}$ \\
\hline $\begin{array}{c}\text { General Contrac- } \\
\text { tor } \\
\left(\mathrm{C}_{1} \square \mathrm{C}_{9}\right)\end{array}$ & $\begin{array}{l}\text { Project manager, Chief engineer, Accountant, Contract- } \\
\text { manager,BIM Engineering manager,BIM Engi- } \\
\text { neer1,BIM Engineer2, Structure subcontractor, Curtain } \\
\text { wall subcontractor, Mechanical and electrical installa- } \\
\text { tion subcontractor, Equipment suppliers, Material sup- } \\
\text { pliers, prefabrication Subcontractor. }\end{array}$ \\
\hline Designer( $\left(\mathrm{D}_{1} \square \mathrm{D}_{12}\right)$ & $\begin{array}{l}\text { Project manager, Architectural design manager, archi- } \\
\text { tect, Structural design manager, Structural engineer, } \\
\text { Electrical design manager, Electrical engineer, Detailed } \\
\text { design manager, engineer1, engineer 2, engineer 3, } \\
\text { engineer 4. }\end{array}$ \\
\hline Others $\left(\mathrm{S}_{1} \square \mathrm{S}_{8}\right)$ & $\begin{array}{l}\text { Investment supervisor, Construction supervisor,BIM } \\
\text { technology consultants, Operator, Facilities engineer, } \\
\text { Property division, Government departments, Third Party }\end{array}$ \\
\hline
\end{tabular}

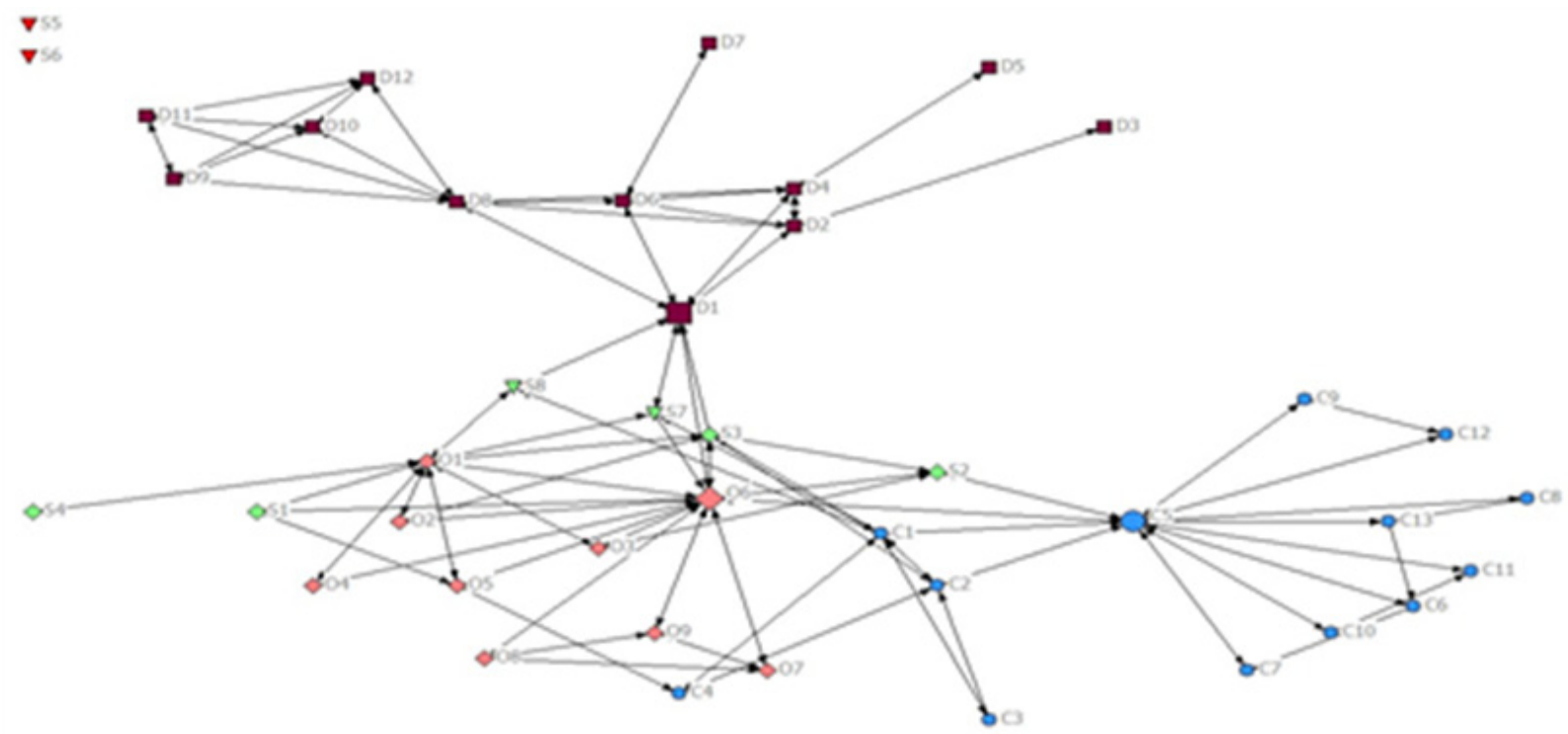

Figure 1. Project network of VP technology communication in Shanghai Center 


\begin{tabular}{|ccc|}
\hline 1 & 2 \\
Betweenness & Betweenness (\%t) \\
6 O6 & 760.577 & 46.377 \\
23 D1 & 625.933 & 38.167 \\
14 C5 & 579.693 & 35.347 \\
30 D8 & 280.000 & 17.073 \\
$1 \mathrm{O} 1$ & 234.873 & 14.322 \\
$10 \mathrm{C} 1$ & 170.962 & 10.425 \\
41 S7 & 112.676 & 6.870 \\
24 D2 & 76.000 & 4.634 \\
28 D6 & 76.000 & 4.634 \\
$40 \mathrm{~S} 6$ & 0.000 & 0.000 \\
\hline
\end{tabular}

Figure 2. Actors' Betweenness Centrality (list of top 10)

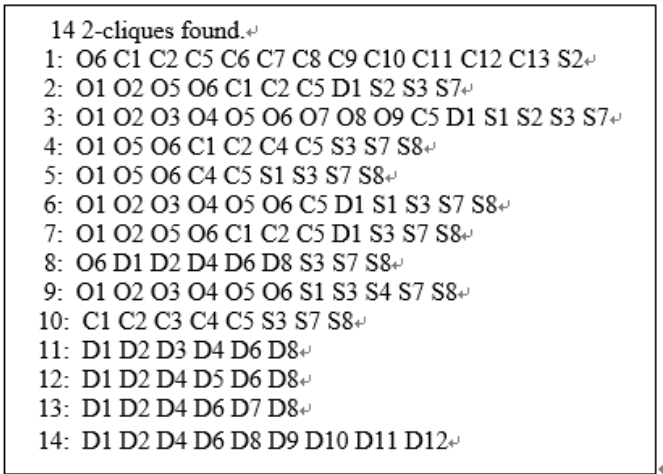

Figure 3. Cohesive subgroup analysis in the network

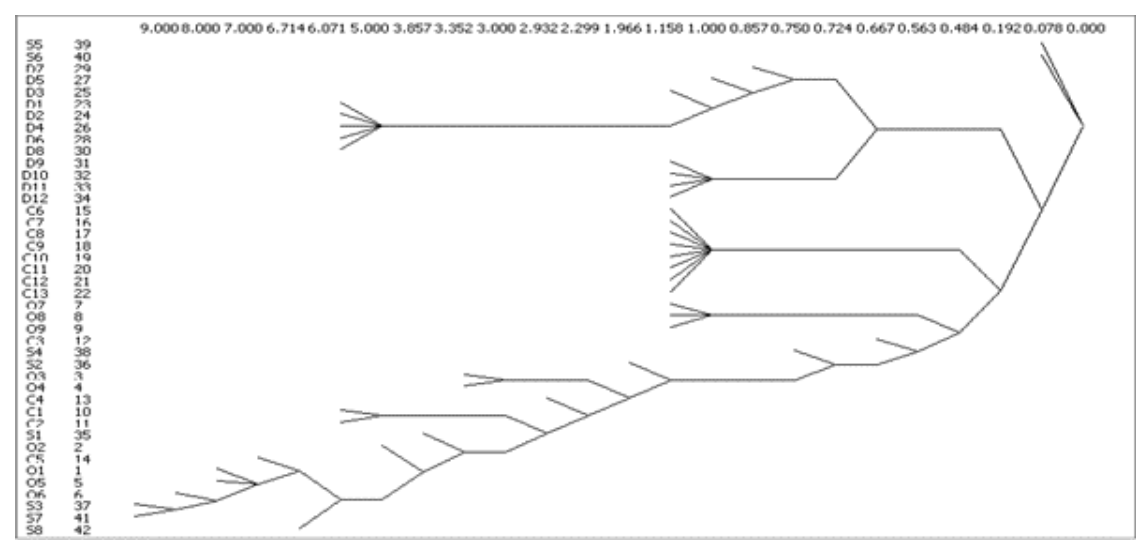

Figure 4. Actors' tree diagram of cliques

Outcomes of cohesive subgroup analysis are shown in Figure 3 and Figure 4. The organization's network can be divided into three major subgroups, which is consistent with the project's organizational structure based on VP technology. Some key nodes play "bridge" roles.

\section{Variables and Model calculations}

Using Matlab software on influencing factors of the Principal Component Analysis, the extraction principle is the principal component which has eigenvalues greater than 1 , cumulative contribution rate $>85 \%$. The cumulative contribution rate of the first eight principal components is $i=87.95>85 \%$. Therefore, these eight new variables could evaluate the social relation cognizance instead of the original 27 variables, and total score models obtained are as follows:

$\mathrm{Y}=0.234 \mathrm{X}_{1}+0.156 \mathrm{X}_{2}-0.075 \mathrm{X}_{3}+0.013 \mathrm{X}_{4}-0.189 \mathrm{X}_{5}+0.068 \mathrm{X}_{6}$ $-0.063 \mathrm{X}_{7}+0.115 \mathrm{X}_{8}+0.174 \mathrm{X}_{9}+0.136 \mathrm{X}_{10}+0.129 \mathrm{X}_{11}+0.049 \mathrm{X}_{12}$ $+0.184 \mathrm{X}_{13}+0.212 \mathrm{X}_{14}+0.203 \mathrm{X}_{15}-0.093 \mathrm{X}_{16}+0.102 \mathrm{X}_{17}+$

$0.236 \mathrm{X}_{18}+0.2 \mathrm{X}_{19}+0.207 \mathrm{X}_{20}+0.131 \mathrm{X}_{21}+0.221 \mathrm{X}_{22}+0.211 \mathrm{X}_{23}$ $+0.207 \mathrm{X}_{24}+0.189 \mathrm{X}_{25}+0.175 \mathrm{X}_{26}+0.198 \mathrm{X}_{27}$

In the above equation, weighting factors of each variable reflect the degree of importance between indicators. Negative values indicate the degree less than the average level while positive values mean above average.

\section{E. Model Analysis and Evaluation}

We make the average value of each indicator (satisfaction, table III) as the horizontal axis and the weight of each indicator (Significance, Eq(10)) as the vertical axis, then draw the Quadrant Map in Figure 5. The key indicators of the BIM cognition of the project and the performance status of each indicator are clearly shown.
TABLE III. SAMPLE DATA DESCRIPTION

\begin{tabular}{|c|c|c|c|c|c|}
\hline Variables & Mean & $\begin{array}{c}\text { standard } \\
\text { deviation }\end{array}$ & Variables & Mean & $\begin{array}{c}\text { standard } \\
\text { deviation }\end{array}$ \\
\hline $\mathrm{X}_{1}$ & 2.01 & .746 & $\mathrm{X}_{15}$ & 3.87 & .963 \\
\hline $\mathrm{X}_{2}$ & 2.75 & 1.048 & $\mathrm{X}_{16}$ & 3.91 & .848 \\
\hline $\mathrm{X}_{3}$ & 3.25 & .980 & $\mathrm{X}_{17}$ & 4.13 & 3.385 \\
\hline $\mathrm{X}_{4}$ & 3.96 & .999 & $\mathrm{X}_{18}$ & 2.52 & 1.033 \\
\hline $\mathrm{X}_{5}$ & 4.26 & .897 & $\mathrm{X}_{19}$ & 3.70 & .858 \\
\hline $\mathrm{X}_{6}$ & 3.1 & .979 & $\mathrm{X}_{20}$ & 4.15 & .930 \\
\hline $\mathrm{X}_{7}$ & 2.93 & .927 & $\mathrm{X}_{21}$ & 3.09 & 1.017 \\
\hline $\mathrm{X}_{8}$ & 3.18 & .948 & $\mathrm{X}_{22}$ & 3.96 & 1.076 \\
\hline $\mathrm{X}_{9}$ & 3.17 & .940 & $\mathrm{X}_{23}$ & 4.08 & .877 \\
\hline $\mathrm{X}_{10}$ & 3.11 & .924 & $\mathrm{X}_{24}$ & 2.63 & 1.142 \\
\hline $\mathrm{X}_{11}$ & 2.93 & .934 & $\mathrm{X}_{25}$ & 3.11 & 0.831 \\
\hline $\mathrm{X}_{12}$ & 3.78 & 1.102 & $\mathrm{X}_{26}$ & 2.05 & 0.987 \\
\hline $\mathrm{X}_{13}$ & 3.03 & 1.010 & $\mathrm{X}_{27}$ & 3.97 & 0.884 \\
\hline $\mathrm{X}_{14}$ & 3.71 & .912 & & & \\
\hline
\end{tabular}

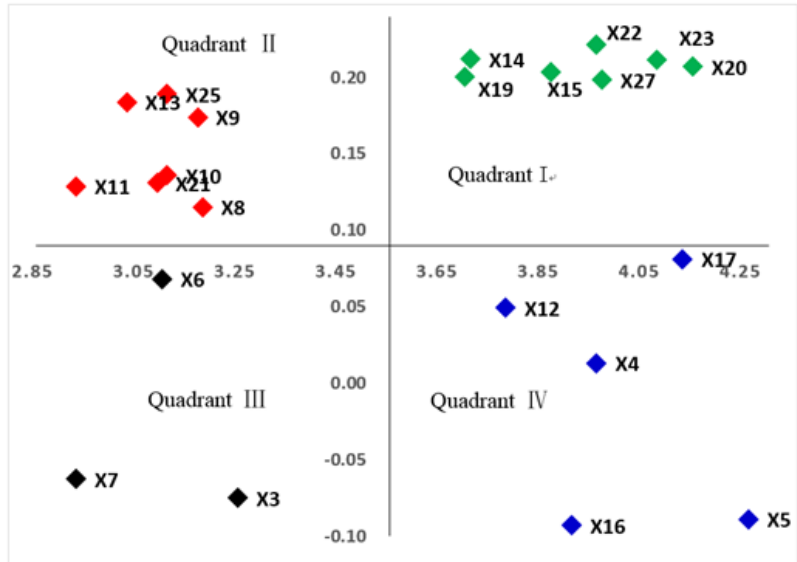

Figure 5. Quadrant Map of cognitive indicators 


\section{a. Quadrant I (Highly Concerned Area)}

There are 7 indicators, including $\mathrm{X}_{14}, \mathrm{X}_{15}, \mathrm{X}_{19}, \mathrm{X}_{20}, \mathrm{X}_{22}$, $\mathrm{X}_{23}, \mathrm{X}_{27}$. It shows that the level of BIM cognition is different between nations, industry and enterprise. International commutation has greatly spur the diffusion to BIM. Larger construction companies are more interested in BIM and owner gradually play the primary role. It is to say that those indicators are moderate in stakeholders' satisfaction and recognition.

\section{b. Quadrant II (Priority Area)}

The indicators of $\mathrm{X}_{8}, \mathrm{X}_{9}, \mathrm{X}_{10}, \mathrm{X}_{11}, \mathrm{X}_{13}, \mathrm{X}_{21}$ and $\mathrm{X}_{25}$ are also important to cognitive model. Most agents think we should take more concerns to understand the values, contracts, skill of engineers, responsibilities, incentive mechanism and organizational structure. Those factors must be improved to maximize the efficiency of VP technology in construction projects.

\section{c. Quadrant III (insignificant Area)}

Just only three indicators of $\mathrm{X}_{3}, \mathrm{X}_{6}$ and $\mathrm{X}_{7}$ belong to the insignificant ones with which agents of the Shanghai Center Project have less interest and less satisfaction in the currently stage. The limitation of their cognition indicates that "myopia insights" is still the most harmful obstacles to BIM implementation in China. The context of civil software, standards and norms, information security and property rights affect the national application in construction industry.

\section{d. Quadrant IV (Maintain Area)}

The indicators of $\mathrm{X}_{4}, \mathrm{X}_{5}, \mathrm{X}_{12}, \mathrm{X}_{16}$, and $\mathrm{X}_{17}$ are not very important to some stakeholders in the project. With the huge investment and ROI expected, they care more about the cost of hardware than that of software. Because BIM maturity of VP technology is still at a low level, using information technology is still under the complex characters in China. It is a long way for the government to establish laws and standards to control the development of VP technology successfully.

\section{CONCLUSION}

The knowledge and cognition of VP technology in construction projects need participants to work together in a team. It depends on the social relation in the organizational network. This study analyses the social relation cognitive model of different actors in Shanghai Center in China. As the most popular VP technology in construction industry, Building Information Modeling is gaining attention gradually by most stakeholders. In the social network of the project, social relation, density, centrality and cohesive subgroup are explored to find the crucial actors, such as BIM manager of owner, BIM engineer of contractor and BIM designer. The analysis of cognitive indicators show that different agents have significant different cognition in the evaluation of important and satisfaction. There is still a long way to improve the performance of indictors and it also needs guidance to be established at the level of the national strategy for BIM.

\section{REFERENCES}

[1] Pratt, Michael J. "Virtual prototypes and product models in mechanical engineering." Virtual Prototyping-Virtual environments and the product design process 10 (1995): 113-128.

[2] Kunz, John, and Martin Fischer. "Virtual design and construction: themes, case studies and implementation suggestions." Center for Integrated Facility Engineering, Working Paper 97 (2005).

[3] Waly, Ahmed F., and Walid Y. Thabet. "A virtual construction environment for preconstruction planning." Automation in construction 12.2 (2003): 139-154 http://dx.doi.org/10.1016/S0926$\underline{5805(02) 00047-\mathrm{X}}$

[4] Yerrapathruni, Sai. Using 4 D CAD and Immersive Virtual Environments to Improve Construction Planning. Diss. The Pennsylvania State University, 2003

[5] Sarshar, Marjan, Per Christiansson, and J. O. H. N. Winter. "Towards virtual prototyping in the construction industry: the case study of the DIVERCITY project." WORLD IT CONFERENCE FOR DESIGN AND CONSTRUCTION, Langkawi, Malaysia. 2004.

[6] Penttilä, H. "Describing the changes in architectural information technology to understand design complexity and free-form architectural expression." ITcon Vol. 11, Special Issue The Effects of CAD on Building Form and Design Quality , pg. 395-408, http://www.itcon.org/2006/29

[7] McGraw-Hill Construction. "THE BUSINESS VALUE OF BIM : Getting Building Information Modeling to the Bottom Line". Smart Market Report.2009

[8] McGraw-Hill Construction. "The Business Value of BIM in Europe". Smart Market Report.2010

[9] Foundation of the Wall and Ceiling Industry. "Building Information Modeling: Understanding and Operating in a New Paradigm”. July 2009.

[10] Gu, Ning, and Kerry London. "Understanding and facilitating BIM adoption in the AEC industry." Automation in construction 19.8 (2010): 988-999. http://dx.doi.org/10.1016/j.autcon.2010.09.002Attia, Shady, and Louvain La Neuve. "Building performance simulation tools: selection criteria and user survey." Louvain Catholic University, Louvain-la-Neuve (2010).

[11] Won, Jongsung, and Ghang Lee. "Identifying the consideration factors for successful BIM projects." Proceedings International Conference. 2010.

[12] Gilligan, Brian, and John Kunz. "VDC use in 2007: significant value, dramatic growth, and apparent business opportunity." Center for Integrated Facility Engineering, Report TR171 (2007).

[13] Yan, Han, and Peter Damian. "Benefits and barriers of building information modelling." 12th International Conference on Computing in Civil and Building Engineering 2008. 2008.

\section{AUTHORS}

*Honglei Liu: (*Corresponding Author) is the $\mathrm{PhD}$ student of School of Economics and Management, Tongji University, Shanghai 200092, China (Email: 666honglei@gmail.com).

Lei Zhang is the PhD student of School of Economics and Management, Tongji University, Shanghai 200092, China.

Guangbin Wang is the professor of School of Economics and Management, Tongji University, Shanghai 200092, China.

This research is financially supported by the Ministry of Science and Technology of China and South Korea Joint Research Projects (2011DFG73520), as well as Natural Science Foundation of China (NSFC) (71272046). It is an extended and modified version of a paper presented at the International Conference on Mechanical Engineering, Automation and Material Science (MEAMS2012), held 22-23 December 2012, Wuhan, China. Received 07 June 2013. Published as resubmitted by the authors 12 June 2013 